\title{
Pengaruh Latihan Lari Zig - Zag Menggunakan Beban Terhadap Peningkatan Keterampilan Dribbling dalam Permainan Sepak Bola Pada Siswa Ekstrakurikuler SMA Negeri 4 SELUMA
}

\author{
Beni Novsir ${ }^{1}$, Defliyanto ${ }^{2}$, Yarmani $^{3}$ \\ ${ }^{123}$ Prodi Penjas, FKIP, Universitas Bengkulu, Kota Bengkulu, Indonesia
}

\begin{tabular}{l}
\hline Info Artikel \\
\hline Sejarah Artikel: \\
Diterima April 2020 \\
Direvisi April 2020 \\
Diterima April 2020 \\
Tersedia online April 2020 \\
\\
\hline- \\
Kata kunci: \\
Zig-Zag Running Training, \\
Dribbling Skills \\
\hline
\end{tabular}

\begin{abstract}
Abstrak
Penelitian ini bertujuan untuk mengetahui pengaruh latihan Lari Zig-Zag Menggunakan Beban Terhadap Peningkatan Keterampilan Dribbling Dalam Permainan Sepak Bola Pada Siswa Ekstrakurikuler SMA NEGERI 4 Seluma. Jenis penelitian yang digunakan dalam penelitian ini adalah penelitian kuantitatif Experimen One Group Pretest-Postest Design. Populasi dalam penelitian ini adalah seluruh ekstrakurikuler di SMA NEGERI 4 Seluma yang berjumlah 30 orang. Hasil penelitian Pengaruh Latihan Lari Zig-Zag Menggunakan Beban Terhadap Peningkatan Keterampilan Dribbling Dalam Permainan Sepak Bola Pada Siswa Ekstrakurikuler SMA NEGERI 4 Seluma diperoleh hasil pretest sebesar 44,03 dan hasil rata-rata posttest sebesar 46,3 dengan selisih 2,27 dan hasil t hitung sebesar 1,738 > dari t table 1,699. Berdasarkan uji statistik dengan $\boldsymbol{\alpha}=\mathbf{5 \%}(0,05)$ bahwa H0 ditolak atau menerima Ha secara sistematik bahwa latihan Lari Zig-Zig berpengaruh terhadap keterampilan Dribbling.
\end{abstract}

\section{Abstract}

This study aims to determine the effect of Zig-Zag Running Exercise Using Loads on Improving Dribbling Skills in Football Games for Extracurricular High School Students in Seluma State High School 4. This type of research used in this research is quantitative research Experiment One Group Pretest-Postest Design. The population in this study were all extracurricular activities in SMA NEGERI 4 Seluma, amounting to 30 people. The results of the study of the Effect of Zig-Zag Running Exercise Using Load Against Improvement of Dribbling Skills in Football Games in Extracurricular High School Students of Seluma 4 Seluma obtained pretest results of 44.03 and posttest average results of 46.3 with a difference of 2.27 and the results of $t$ count is $1,738>$ from $t$ table 1,699. Based on statistical tests with $\alpha=5 \%(0.05)$ that $\mathrm{H} 0$ is 


\begin{tabular}{lr}
\hline & $\begin{array}{l}\text { rejected or Ha is received systematically that Zig-Zag Running } \\
\text { exercises affect Dribbling skills. }\end{array}$ \\
& \\
\hline $\begin{array}{l}\text { Alamat yang sesuai: Jln. Lintas Barat Sumatera Kab. Kaur } \\
\text { Email }\end{array} \quad$ beninovsir@gmail.com & ISSN (online) \\
ISSN (cetak)
\end{tabular}

\section{PENDAHULUAN}

Olahraga merupakan hal yang sangat dekat dengan manusia kapan dan dimana saja berada. Sebab olahraga merupakan salah satu kebutuhan hidup yang harus dipenuhi oleh setiap manusia. Saat ini hampir semua orang senang berolahraga. Olahraga telah menjadi salah satu gaya hidup yang tidak dapat di pisahkan dari masyarakat dunia saat ini. Tujuan seseorang dalam berolahraga bermacam-macam, ada yang bertujuan untuk sekedar mengisi waktu luang, rekreasi, kesehatan, kebugaran ataupun untuk pencapaian prestasi dan mengharumkan nama bangsa. Di Indonesia, permainan sepakbola cukup memasyarakat dan digemari oleh semua lapisan masyarakat. Bisa di katakan rakyat indonesia di kenal sebagai penggemar sepak bola paling fanatik. Sudah lama di indonesia menyelenggarakan berbagai kompetensi dari level paling rendah hingga kompetensi tingkat nasional. Di indonesia, badan yang menangani sepakbola adalah Persatuan Sepakbola Seluruh Indonesia ( PSSI ). PSSI ini berdiri pada 19 April 1930 di Yogyakarta. Pada awal berdirinya, PSSI sendiri adalah singkatan dari Persatoean Sepakraga Seloeroeh Indonesia (Andi Cipta Nugraha, 2012:20).

Sepak bola merupakan olahraga beregu atau tim yang dimainkan oleh 2 tim yang berlawanan dengan aturan yang sudah ditentukan, masing - masing tim terdiri dari 11 pemain termasuk 1 penjaga gawang. Tujuan permainan Sepak bola adalah pemain memasukkan bola sebanyak - banyaknya ke gawang lawadan berusaha menjaga gawangnya agar tidak kemasukan. Perlu keterampilan atau kemampuan yang dikuasai dalam bermian sepak bola. Keterampilan sepak bola antara lain, dribbling, passing, control, shooting, dan heading. Salah satu diantaranya yaitu dribbling, dribbling adalah keterampilan dasar dalam sepak bola karena semua pemain harus mampu menguasai bola saat sedang bergerak, berdiri, atau bersiap untuk melakukan operan atau tembakan ( Danny Mielke, 2007 : 1 ). sedangkan Menurut Sukatamsi ( 2005 : 3.3 ) Menggiring bola dapat diartikan dengan gerakan lari menggunakan bagian kaki mendorong bola agar bergulir terus-menerus di atas tanah. Menggiring bola hanya dilakukan pada saat-saat yang menguntungkan saja, yaitu bebas dari lawan.

Menggiring bola merupakan salah satu teknik dasar yang cukup memiliki peranan penting dalam permainan sepak bola tidak heran jika para pengamat sepakbola khususnya menyatakan bahwa mahirnya seorang pemain dapat dilihat pada bagaimana seorang pemain tersebut menggiring bola. Salah satu program pembinaan sepakbola yang dilakukan oleh satuan pendidikan atau sekolah baik tingkat SD, SMP, maupun SMA adalah dengan mengadakan ekstrakurikuler. Jenis kegiatan ekstrakurikuler beragam mulai dari bidang seni misalnya ektrakurikuler seni tari, drama, seni rupa, dan seni musik. Bidang keolahragaan misalnya ekstrakurikuler sepakbola, basket, bolavoli, dan atletik. Tujuan dari ektrakurikuler adalah menyiapkan anak 
menjadi orang yang bertanggung jawab, menemukan dan mengembangkan minat dan bakat pribadinya, serta menyiapkan dan mengarahkan pada suatu spesialisasi, misalnya: atlet, seniman dan sebagainya. Berdasarkan hasil wawancara awal yang peneliti lakukan di SMA Negeri 4 Seluma yang beralamat di desa Sendawar, Kecamatan Semidang Alas Maras, Kabupaten Seluma, Provinsi Bengkulu. kegiatan ekstrakurikuler sepak bola diikuti oleh 30 siswa dari kelas X - XI. Ekstrakurikuler sepak bola di SMA Negeri 4 Seluma dilaksanakan seminggu dua kali pada hari rabu dan Sabtu mulai pukul 15.00 WIB - 17.00 WIB. Alat yang digunakan pada kegiatan ektrakurikuler sepakbola di SMA Negeri 4 Seluma ini meliputi 10 buah bola, rompi 15 , cones sebanyak 20 buah dan tidak memiliki gawang kecil, sedangkan untuk lapangan berlatih menggunakan lapangan milik desa Bandung Agung, Kecamatan Semidang Alas yang tidak jauh berada di dekat sekolah. SMA Negeri 4 Seluma merupakan salah satu diantara banyak sekolah yang mengutamakan prestasi akademik daripada non-akademik, sehingga prestasi non-akademik khususnya ekstrakurikuler sepakbola masih belum berprestasi karena tidak terlalu diutamakan.

\footnotetext{
Berdasarkan hasil pengamatan yang peneliti lakukan Kegiatan ekstrakurikuler yang diadakan di SMA Negeri 4 Seluma sangat tidak mendukung prestasi sepak bola yang diraih. Dengan latihan yang di lakukan sebanyak dua kali dalam seminggu tidak mampu meningkatkan prestasi. Keberadaan lapangan sepak bola yang cukup dekat dengan lokasi sekolah, seharusnya dapat mendukung kemajuan sepak bola di SMA Negeri 4 Seluma. Dalam setiap perlombaan sepak bola tingkat sekolah menengah atas yang diadakan, baik dalam rangka memeriahkan peringatan
}

kemerdekaan Republik Indonesia ataupun dalam turnamen lainnya belum sama sekali memperoleh hasil yang memuaskan. Bahkan dalam turnamen terakhir yaitu turnamen pekan olahraga pelajar Kabupaten (POPKAB) yang diadakan oleh Dispora Seluma dalam ajang pencarian pemain yang akan dibawa ke tingkat POPDA. tim SMA Negeri 4 seluma hanya mampu mencapai babak 8 besar. SMA Negeri 4 Seluma di kalahkan oleh SMA N 5 Seluma dengan skor 3-1. Kekalahan tim SMA Negeri Seluma disebabkan oleh beberapa faktor, salah satunya yaitu masih rendahnya kemampuan dribbling pada pemain.

Dalam upaya pembinaan untuk meningkatkan keterampilan menggiring bola (dribbling) berbagai macam pelatihan dapat dilakukan khususnya pelatihan lari zig-zag menggunakan beban. Kalau beban latihan terlalu ringan dan tidak di tambah (tidak diberi overload), maka berapa lama pun kita berlatih, betapa sering pun kita berlatih, atau sebagaimana capik pun kita mengulang-ulang latihan tersebut, peningkatan prestasi tidak akan mungkin terjadi, atau kalau pum ada peningkatan, peningkatan itu hanya kecil sekali (Harsono, 2015: 52). Berdasarkan hasil pengamatan (observasi) yang peneliti lakukan terlihat bahwa keterampilan menggiring bola (dribbling) yang dilakukan siswa peserta ekstrakurikuler masih rendah, hal ini dapat dilihat pada saat turnamen, dribbling pemain masih bisa di block oleh lawan dengan mudah. Hal ini di karnakan kurangnya latihanlatihan yang terarah untuk meningkatkan kondisi fisik yang menyangkut teknik dribbling pada peserta ekstrakurikuler. Karna kurangnya latihan yang terarah sehingga keterampilan menggiring bola belum maksimal. Bertitik tolak dari uraian di atas, penulis tertarik melakukan penelitian dengan judul "pengaruh latihan lari zig-zag menggunakan beban terhadap 
peningkatan keterampilan dribbling dalam permainan sepakbola pada siswa ekstrakurikuler di SMA Negeri 4 Seluma".

\section{METODE}

Metode penelitian adalah keseluruhan rencana untuk mendapatkan jawaban atas pernyataan yang sedang dipelajari dan untuk menangani berbagai tantangan terhadap bukti penelitian yang layak. Dalam merancang penelitian ini, peneliti memutuskan mana yang spesifik mana yang akan diadopsi dan apa yang akan mereka lakukan untuk meminimalkan bias dan meningkatkan interpretabilitas hasil.

Sesuai dengan judul penelitian "pengaruh latihan lari zig-zag menggunakan beban terhadap peningkatan keterampilan dribbling dalam permainan sepakbola pada siswa ekstrakurikuler di SMA Negeri 4 Seluma". maka penelitian ini berjenis penelitian eksperimen kuantitatif. Penelitian ini di bagi menjadi 3 tahapan yakni Pretest, pemberian perlakuan (Treatmen) dan Posttest. Desain yang di gunakan dalam penelitian ini adalah One Group Pretest-Posttest Design. Dalam design ini tidak menggunakan kelompok kontrol dan subyek tidak ditempat kan secara acak. Kelebihan dari Design ini adalah dilakukan nya Pretest dan Posttest sehingga dapat diketahui pasti perbedaan hasil perlakuan yang diberikan (Treatment).

\section{HASIL}

Sampel dalam penelitian ini siswa di SMA NEGERI 4 Seluma. Sampel dianjurkan untuk mengikuti tes awal terlebih dahulu (pretest) yang bertujuan untuk mengetahui kemampuan dribbling. Pada saat melakukan tes menggiring bola melewati halang rintang peserta diberikan kesempatan sebanyak dua kali untuk mencari hasil yang terbaik. Setelah melakukan Pretest kemudian seluru siswa mengikuti program latihan lari zig $-z a g$ menggunakan beban yang merupakan bagian dari penelitian tersebut pada hari yang sudah dijadwalkan. Setelah mengikuti perlakuan (treatmen) maka siswa akan diuji kembali dengan menggunakan test yang sama yaitu dribbling dengan dua kali percobaan.

Dari data yang sudah diperoleh, hasil pretest sebesar 44,03 dan hasil ratarata posttest sebesar 46,3 dengan selisih 2,27. Dari hasil penelitian menunjukkan bahwa selisih mean antara pretest dan posttest siswa setelah mengikuti program latihan lari zig - zag menggunakan beban sebanyak 18 kali pertemuan dapat menunjukkan peningkatan terhadap keterampilan dribbling siswa. Hasil ratarata tersebut dengan waktu latihan yang relatif pendek hanya dapat menyebabkan perubahan akibat latihan yang bersifat sementara dan akan mudah sekali kembali pada keadaan semula. Namun, waktu latihan yang relatif lama akan menyebabkan terjadinya perubahan akibat latihan yang bersifat tetap dan tidak bersifat sementara. dari hasil data yang telah terkumpul t hitung sebesar 1,738 > dari t tabel 1,699. Maka data hasil ada pengaruh yang signifikan latihan lari zigzag menggunakan beban. Dengan demikian hipotesis yang berbunyi "Ada pengaruh latihan lari zig-zag menggunakan beban terhadap peningkatan keterampilan dribbling dalam permainan sepakbola pada siswa ekstrakurikuler di SMA Negeri 4 Seluma”, diterima.

Dengan diberikannya program latihan lari zig - zag maka dapat dilihat dari hasil program latihan yang diberikan menunjukkan adanya peningkatan pada keterampilan dribbling di SMA NEGERI 4 Seluma. Dilihat dari hasil rata-rata di atas, maka latihan lari zig - zag 
berpengaruh terhadap peningkatan menggiring bola. Jadi dapat dikatakan bahwa latihan lari zig - zag menggunakan beban dapat digunakan sebagai salah satu latihan untuk meningkatkan keterampilan menggiring bola.

\section{PEMBAHASAN}

Latihan yang dilaksanakan selama 18 kali pertemuan terbukti berhasil memberikan pengaruh terhadap peningkatan keterampilan dribbling siswa di SMA NEGERI 4 Seluma. Seperti yang dikatakan Apta dan Febi, (2015:47) latihan adalah aktifitas untuk meningkatkan kualitas fungsi sistem organ tubuh manusia sehingga mempermudah atlet dalam penyempurnaan geraknya dan latihan adalah proses dimana seseorang atlet dipersiapkan untuk peforma tertinggi (Bompa dan Gregory, 2009:2). Kelebihan dari latihan ini adalah ketika atlet melakukan menggiring bola melewati rintangan setelah dilakukan gerakan tanpa menggunakan rintangan atlet akan merasa kelincahan tanpa beban . Dalam memberikan program latihan lari zig - zag menggunakan beban peneliti memberikan latihan dengan berbagai macam variasi, yang bertujuan siswa dapat berlatih dengan gembira dan tidak mengalami kejenuhan ketika latihan serta membuat latihan menjadi tidak monoton. Teori - teori diatas memperkuat bahwa latihan lari zig - zag menggunakan beban berpengaruh terhadap peningkatan dribbling di SMA NEGERI 4 Seluma. Peningkatan keterampilan dribbling terlihat pada perbandingan perubahan rata-rata pretest dan posttest. Dari data yang sudah diperoleh, hasil Pretest sebesar 44,03 dan hasil rata-rata posttest sebesar 46,3 dengan selisih 2,27.

Dari hasil penelitian menunjukkan bahwa selisih Mean antara pretest dan posttest siswa setelah mengikuti program latihan lari zig - zag menggunakan beban sebanyak 18 kali pertemuan dapat menunjukkan peningkatan terhadap keterampilan dribbling. Hasil rata-rata tersebut dengan waktu latihan yang relatif pendek hanya dapat menyebabkan perubahan akibat latihan yang bersifat sementara dan akan mudah sekali kembali pada keadaan semula. Namun, waktu latihan yang relatif lama akan menyebabkan terjadinya perubahan akibat latihan yang bersifat tetap dan tidak bersifat sementara.

Dan dari hasil $\mathrm{t}$ hitung sebesar $1,738>$ dari $t$ tabel 1,699. Maka data hasil ada pengaruh yang signifikan latihan lari zig - zag menggunakan beban terhadap keterampilan dribbling. Dengan demikian hipotesis yang berbunyi "Ada Pengaruh Latihan Lari Zig- Zag Menggunakan Beban Terhadap Peningkatan Keterampilan Dribbling Dalam Permainan Sepak Bola Pada Siswa Ekstrakurikuler SMA NEGERI 4 Seluma", diterima. Mengingat pentingnya kelincahan dalam aktifitas fisik maka perlu sekali upaya untuk meningkatkan kelincahan Siswa di SMA NEGERI 4 SELUMA. Keterampilan Dribbling siswa dapat meningkat apabila latihan dilakukan secara terprogram, terencana, dan dilakukan dengan benar. Dengan demikian dapat di simpulkan bahwa penelitian yang telah dilakukan dengan pemberian latihan lari zig - zag menggunakan beban terbukti dapat meningkatkan keterampilan dribbling siswa di SMA NEGERI 4 Seluma.

\section{SIMPULAN DAN SARAN}

Berdasarkan hasil penelitian dapat disimpulkan bahwa latihan lari zig- zag menggunakan beban berpengaruh terhadap peningkatan keterampilan dribbling dalam permainan sepak bola pada siswa ekstrakurikuler SMA NEGERI 4 Seluma. Peningkatan keterampilan dribbling terlihat pada perbandingan perubahan rata- 
rata Pretest dan Posttest. Dari data yang sudah diperoleh, hasil Pretest sebesar 44,03 dan hasil rata-rata Posttest sebesar 46,3 dengan selisih 2,27. Hasil penelitian menunjukkan bahwa selisih Mean antara Pretest dan Posttest siswa setelah mengikuti program latihan lari zig - zag menggunakan beban sebanyak 18 kali pertemuan dapat menunjukkan peningkatan terhadap keterampilan dribbling. Dan dari hasil t hitung sebesar 1,738 > dari t tabel 1,699. Bahwa ada pengaruh yang signifikan latihan lari zigzag menggunakan beban terhadap keterampilan dribbling. Dengan demikian hipotesis (Ha) yang berbunyi "Ada Pengaruh Latihan Lari Zig- Zag Menggunakan Beban Terhadap Peningkatan Keterampilan Dribbling Dalam Permainan Sepak Bola Pada Siswa Ekstrakurikuler SMA NEGERI 4 Seluma", diterima.

Berdasarkan hasil penelitian yang telah dilakukan, peneliti berharap dan memberikan saran sebagai berikut :

1. Bagi guru atau pelatih untuk memberikan latihan yang lebih bervariasi lagi sebagai upaya untuk mengurangi kejenuhan latihan.

2. Sebaiknya siswa senantiasa meningkatkan latihan lari Zig - Zag Menggunakan beban , untuk mencapai prestasi yang lebih baik.

3. Bagi peneliti yang ingin melanjutkan penelitian ini agar dapat menjadikan penelitian ini sebagai bahan informasi dan penelitian dengan populasi dan sampel yang berbeda dengan jumlah yang lebih banyak lagi.

\section{DAFTAR PUSTAKA}

Aji, Insan. 2012. Ukuran Lapangan Sepak Bola di http://www.kabarsepakbola. (Akses 20 Februari pukul 20.00 wib).

Andi, Cipta. 2012. Mahir Sepak Bola. Bandung : Nuansa Cendikia.

Arikunto, Suharsimi. 2006. Prosedur Penilaian Suatu Pendekatan Praktik. Jakarta: PT Reneka Cipta.

Arsil. 2012. Evaluasi Pendidikan Jasmani Olahraga. Malang : Pakar Karya.

Erlangga. 2017. Panduan Kepelatihan Seapak Bola Anak. Jakarta : Esensi.

Jumaking, J. (2020). PENGARUH DAYA LEDAK TUNGKAI, KOORDINASI MATA KAKI DAN PERCAYA DIRI TERHADAP KEMAMPUAN SHOOTING KE GAWANG DALAM PERMAINAN SEPAKBOLA PADA SISWA SMAN 2 KOLAKA. Kinestetik: Jurnal Ilmiah Pendidikan Jasmani, 4(1), 122-131.

Kurniawan, Feri. 2011. Buku Pintar Olahraga. Jakarta : Laskar Aksara.

Mielke, Danny. 2007. Dasar-Dasar Sepak Bola. Bandung : Pakar Karya.Terbuka.

Scheunemann, Timo. 2012. Kurikulum \& Pedoman Dasar Sepak Bola Indonesia. Jakarta : PSSI.

Subagiyo. 2004. Perencanaan Pembelajaran Penjaskes. Jakarta : Universitas Terbuka

Sukatamsi. 2005. Permainan Besar 1 Sepak Bola. Jakarta : Universitas Terbuka

Sugiyono. 2006. Metode Penelitian Kuantitatif Kualitatif Dan $R \& D$. Bandung: Alfabeta. 
Supardi. 2017. Statiska Penelitian Pendidikan. Depok: Rajawali Pers.

Wiarto, Giri. 2013. Fisiologi Dan Olahraga. Yogyakarta : Graha Ilmu.

Razbie, R. Y., Nurudin, A. A., \& Soleh, M. (2018). Pengaruh Latihan Lari ZigZag terhadap Penguasaan Teknik Dasar Dribbling pada Permainan Sepakbola Ekstrakurikuler SDN Sungapan Kecamatan Kadudampit 2018. utile: Jurnal Kependidikan, 4(2), 47-57.

Ruslan, R., Hamdiana, H., Simon, S., \& Ismawan, H. (2020). PENGARUH LATIHAN PLYOMETRIC TERHADAP KEMAMPUAN SHOOTING SEPAK BOLA PADA CLUB PDL SAMARINDA. Kinestetik: Jurnal Ilmiah Pendidikan Jasmani, 4(1), 33-40. 